\begin{tabular}{lc|}
\hline KURNAL ANALIS KESEHATAN & Klinikal Sains 7 (2) (2019) \\
KLIVERSITAS & KLINIKAL SAINS \\
\hline ABDURRAB & http://jurnal.univrab.ac.id/index.php/klinikal \\
\hline
\end{tabular}

\title{
Hubungan Kualitas Pelayanan Laboratorium Dengan Loyalitas Pelanggan Laboratorium Di Rumah Sakit Muhammadiyah Ahmad Dahlan Kota Kediri
}

\author{
Petro Dwi Siswanto, Oktovina Rizky Indrasari ${ }^{1}$, Elok Retno anggraini ${ }^{2}$ \\ Program Studi teknologi laboratorium medis, Fakultas ilmu kesehatan, institut ilmu kesehatan BW \\ Kediri Jawa Timur \\ Jl.KH. Wahid Hasyim No. 65 Bandar Lor Mojoroto Kota Kediri Jawa Timur \\ Telp. (0354) 773299 \\ Alamat e-mail: petrodwi@gmail.com
}

\section{Info Artikel \\ Sejarah Artikel: \\ Diterima Juni 2019 \\ Disetujui November 2019 \\ Dipublikasikan Desember 2019}

Keywords: kualitas pelayanan, loyalitas pelanggan, pelayanan laboratorium.

\begin{abstract}
Abstrak
Latar Belakang : Kualitas jasa pelayanan kesehatan akan sangat ditentukan apabila kebutuhan para pengguna jasa bisa terpenuhi dan diterima tepat waktu. Jika konsumen merasa puas karena kualitas pelayanan yang baik, maka akan memperlihatkan peluang yang besar untuk melakukan kunjungan kembali. Tujuan : Penelitian ini untuk mengetahui hubungan kualitas pelayanan dengan loyalitas pelanggan di Laboratorium Rumah Sakit Muhammadiyah Ahmad Dahlan Kota Kediri. Penelitian ini menggunakan Metode : Penelitian survei analitik. Pengambilan sampel pada penelitian ini menggunakan teknik Quota sampling, kuota yang telah ditentukan sebanyak 49 responden terdiri dari 25 jenis kelamin perempuan dan 24 jenis kelamin laki-laki. Instrumen penelitian menggunakan Kuesioner. Hasil : Penelitian diperoleh kualitas pelayanan laboratorium dengan kategori baik $(91,8 \%)$ dan loyalitas pelanggan laboratorium dalam kategori loyal $(89,8 \%)$, berdasarkan analisis bivariat diperoleh nilai Sig= 0,047 yang artinya terdapat hubungan antara kualitas pelayanan laboratorium dengan loyalitas pelanggan Laboratorium Rumah Sakit Muhammadiyah Ahmad Dahlan Kota Kediri. Kesimpulan : Dari penelitian ini adalah terdapat hubungan yang bermakna antara kualitas pelayanan laboratorium dengan loyalitas pelanggan laboratorium di Rumah Sakit Muhammadiyah Ahmad Dahlan Kota Kediri dengan kualitas pelayanan memuaskan. Laboratorium Rumah Sakit Muhammadiyah Ahmad Dahlan Kota Kediri harus mampu mempertahankan dan meningkatkan kualitas pelayanan dengan cara selalu merancang kualitas jasa dengan baik dengan memberikan pelayanan yang memuaskan sehingga dapat menarik pelanggan untuk berkunjung ke Laboratorium Rumah Sakit Muhammadiyah Ahmad Dahlan Kota kediri
\end{abstract}

Kata Kunci: kualitas pelayanan, loyalitas pelanggan,pelayanan laboratorium.

\section{Abstract}

Background : Quality of health care services will be very determined if the needs of service users can medid and received on time. If consumers feel satisfied because of the good quality of service, it will show a great opportunity to make a 
return visit. This research aims to determine the relationship of service quality with customer loyalty in the Muhammadiyah Ahmad Dahlan Hospital Laboratory Kediri City. This research using analytical survey research methods. Sampling in this research uses Quota sampling technique, the quota that has been determined is 49 respondents consisting of 25 female gender and 24 male gender. Research instruments using questionnaires. Results showed the quality of laboratory services with category good (91.8\%) and customer loyalty in the laboratory category loyal(89,8\%), bivariate analysis results obtained 0,047 which means there is a correlation service quality Laboratory With Customer Loyalty Muhammadiyah Ahmad Dahlan Hospital Laboratory Kediri City. Conclusions of This research is a significant correlation the Quality of Services and Laboratory Customer Loyalty in Muhamadiyah Ahmad Dahlan Hospital, Kediri City with satisfying service quality. Muhammadiyah Ahmad Dahlan Hospital Laboratory, Kediri City must be able to maintain and improve the quality of service in a way always designing service quality well by providing services satisfying so that it can attract customers to visit Laboratory of Muhammadiyah Ahmad Dahlan Hospital in Kediri City.

(C) 2019 Universitas Abdurrab

\footnotetext{
Alamat korespondensi: Kediri.Jawa Timur

E-mail: petrodwi@mail.com

ISSN 2338-4921
}

\section{PENDAHULUAN}

Pelayanan kesehatan merupakan bagian integral yang tidak dapat terpisahkan dari upaya peningkatan kualitas sumber daya manusia. Pada saat ini perkembangan ilmu dan teknologi kesehatan yang begitu pesat semakin meningkat dan mengarah pada sistem pelayanan yang terintegrasi dan terspesialisasi. Semakin pesat laju perkembangan, semakin besar pula tuntutan masyarakat dalam mendapatkan pelayanan kesehatan yang lebih baik (sastrimal, 2010). Ketersediaan saranan pelayanan dan tenaga kesehatan yang berkualitas serta anggaran yang memadai, akan berpengaruh pada status kesehatan masyarakat. Pengetahuan dan keterampilan petugas kesehatan yang di imbangi dengan kelengkapan sarana akan memberikan pelayanan yang maksimal sehingga akan mampu mengurangi atau mengatasi masalah kesehatan yang timbul di masyarakat (Farich, 2012). Mutu pelayanan kesehatan masyarakat perlu terus di tingkatkan untuk meningkatkan derajat kesehatan masyarakat. Untuk mewujudkan keadaan sehat tersebut banyak hal perlu di lakukan, salah satu upaya yang di nilai mempunyai peranan yang cukup penting adalah penyelenggaraan pelayanan kesehatan. Keberhasilan penyelenggaraan pelayanan kesehatan di nilai melalui peningkatan mutu pelayanan (Anggraini dan Rohmani, 2012). Menururt Musaddad, 2011 dalam (Afif Ghaffar, 2017) Jika konsumen merasa puas karena mutu pelayanan yang baik, ia akan memperlihatkan peluang yang besar untuk melakukan pembelian ulang. Persaingan yang makin ketat, mengharuskan perusahaan tetap menjaga keberlangsungannya, dengan cara mempertahankan pelanggannya. Hal ini dapat dilakukan dengan menanamkan persepsi subyektif kepada konsumen saat pengkonsumsian 
Petro Dwi Siswanto, Oktovina Rizky Indrasari, Elok Retno anggraini / Jurnal Analis Kesehatan Klinikal Sains 7 (2) (2019)

barang atau jasa hingga konsumen berminat untuk melakukan pembelian ulang. Menurut Kepmenkes No. 129 tahun 2008 dalam (Aulia Nur, 2014) rumah sakit adalah sarana kesehatan yang menyelenggarakan pelayanan kesehatan perorangan meliputi pelayanan promotif, preventif, kuratif dan rehabilitatif yang menyediakan pelayanan rawat inap, rawat jalan, dan gawat darurat. Tugas rumah sakit sebagai institusi pelayanan kesehatan adalah memberikan pelayanan kesehatan yang bermutu, dan bertanggung jawab terhadap masyarakat terutama di wilayah cakupannya, sedangkan fungsi rumah sakit adalah menyelenggarakan pelayanan spesialistik atau medik sekunder dan pelayanan subspesialistik atau medik tersier. Oleh karena itu produk utama rumah sakit adalah pelayanan medik. Pelayanan laboratorium kesehatan merupakan bagian yang tidak terpisahkan dari pelayanan pada rumah sakit. Laboratorium kesehatan sebagai unit kesehatan penunjang medis, diharapkan dapat memberikan informasi yang teliti dan akurat tentang aspek laboratoris terhadap specimen atau sampel yang pengujiannya dilakukan di laboratorium untuk memberikan kepercayaan serta kenyamanan dalam melakukan pemeriksaan. Berdasarkan dari kunjungan pasien 4 bulan terakhir di laboratorium Rumah Sakit Muhammadiyah Ahmad Dahlan pasien rawat inap pada bulan januari sebanyak 1219 pasien, februari 1089 pasien, maret 1233 pasien, april 1106 pasien, dan pada pasien rawat jalan pada bulan januari sebanyak 886 pasien, februari 788 pasien, maret 876 pasien, dan april sebanyak 717 pasien, hal ini menunjukkan penurunan jumlah kunjungan pasien pada pasien rawat jalan pada 4 bulan terakhir di laboratorium Rumah Sakit Muhammadiyah Ahmad Dahlan kota Kediri. Pada penelitian yang di lakukan Santoso (2013) tentang pengaruh kualitas pelayanan terhadap loyalitas pelanggan laboratorium klinik populer Surabaya bahwa ada hubunganya antara kualitas pelayanan dengan loyalitas pelanggan dengan tingkat koefesien berganda sebesar $84,9 \%$ yang menunjukkan bahwa hubungan antara variable-variabel sangatlah erat. Dari latar belakang di atas dan untuk meningkatkan kualitas pelayanan dan kemajuan laboratorium penulis tertarik ingin mengetahui hubungan kualitas pelayanan laboratorium dengan loyalitas pengujung di laboratorium Rumah Sakit Muhammdiyah Ahmad Dahlan kota Kediri.

\section{METODE}

Dalam penelitian ini menggunakan metode penelitian survei analitik yaitu penelitian yang dilakukan untuk mencari hubungan antar variabel bebas dan variabel terikat dengan desain penelitian Cross Sectional yaitu suatu penelitian untuk mempelajari dinamika korelasi antara faktor-faktor beresiko dengan efek, dengan cara pendekatan, observasi atau pengumpulan data sekaligus pada suatu saat (Notoatmodjo,2010). Pada penelitian ini, peneliti melakukan penelitian dengan melakukan wawancara menggunakan kuesioner kepada responden dalam 
Petro Dwi Siswanto, Oktovina Rizky Indrasari, Elok Retno anggraini / Jurnal Analis Kesehatan Klinikal Sains 7 (2) (2019)

waktu yang bersamaan. Teknik sampling yang digunakan dalam penelitian ini adalah Quota sampling. dilakukan dengan cara menetapkan sejumlah anggota sampel secara quotum atau jatah. Tehnik sampling ini di lakukan dengan cara : pertama-tama menetapkan berapa besar jumlah sampel yang di perlukan atau menetapkan quotum (jatah). Kemudian jumlah atau quotum itulah yang di jadikan dasar untuk mengambil unit sampel yang di butuhkan. Anggota populasi manapun yang akan diambil tidak menjadi soal, yang penting jumlah quotum yang sudah ditetapkan dapat di penuhi. (Notoatmodjo,2012). Populasi yang digunakan pada penelitian ini di ambil dari jumlah pasien rawat jalan yg malakukan pemeriksaan laboratorium pada bulan januari sampai dengan april 2018 yang jumlahnya sebanyak 3.267 pasien Laboratorium Rumah Sakit Muhammadiyah Ahmad Dahlan di kota Kediri. Penelitian ini dilaksanakan pada bulan Juni 2018 di Laboratorium Rumah Sakit Muhammadiyah Ahmad Dahlan.

\section{HASIL DAN PEMBAHASAN}

Karakteristik responden pada peneliti ini sebagai berikut :

a. Karakteristik responden berdasarkan jenis kelamin

Tabel 1. Karakteristik Jenis Kelamin responden

\begin{tabular}{llcc}
\hline \multicolumn{1}{c}{ No. } & \multicolumn{1}{c}{ Jenis Kelamin } & Jumlah Pasien & Persentase (\%) \\
\hline $\mathbf{1 .}$ & Laki-laki & 24 & 49 \\
\hline 2. & Perempuan & 25 & 51 \\
\hline Total & & 49 & 100
\end{tabular}

Sumber : Data Primer, 2018

Berdasarkan tabel .1 dijelaskan bahwa dari 49 responden yang banyak melakukan pemeriksaan adalah jenis kelamin perempuan sebanyak 25 pasien (51\%).

b. Karakteristik responden Berdasarkan Umur

Tabel 2 Karakteristi Umur responden

\begin{tabular}{cccc}
\hline No. & Umur & Jumlah Responden & Persentase (\%) \\
\hline $\mathbf{1 .}$ & $<20$ Tahun & 6 & 12,2 \\
\hline $\mathbf{2 .}$ & $21-35$ Tahun & 20 & 40,9 \\
\hline 3. & $>36$ Tahun & 23 & 46,9 \\
\hline Total & & 49 & 100 \\
\hline
\end{tabular}

Sumber : Data Primer, 2018 
Petro Dwi Siswanto, Oktovina Rizky Indrasari, Elok Retno anggraini / Jurnal Analis Kesehatan Klinikal Sains 7 (2) (2019)

Berdasarkan tabel 2 di jelaskan bahwa dari 49 responden tingkatan usia yang sering melakukan pemeriksaan adalah pada tingkatakan umur $>36$ tahun sebanyak 23 responden $(46,9)$.

c. Karakteristik Responden Berdasarkan Tingkat Pendidikan

Tabel 3. Karakteristik Tingkat pendidikan responden

\begin{tabular}{clcc}
\hline No. & Tingkat Pendidikan & Jumlah & Persentase(\%) \\
\hline $\mathbf{2 .}$ & SD & 4 & 8.2 \\
\hline $\mathbf{3 .}$ & SMP & 16 & 32.7 \\
\hline $\mathbf{3}$. & SMA & 23 & 46.9 \\
\hline $\mathbf{4 .}$ & Diploma & 6 & 12.2 \\
\hline $\mathbf{5 .}$ & Sarjana & 0 & 0 \\
\hline Total & & 49 & 100 \\
\hline
\end{tabular}

Sumber : Data Primer, 2018

Berdasarkan tabel 3 diketahui bahwa dari 49 responden, tingkat pendidikan SMA terakhirlah yang sering melakukan pemeriksaan yaitu sebanyak 23 pasien $(46,9 \%)$.

d. Karakteristik Responden Berdasarkan Jenis Pekerjaan

Tabel 4. Karakteristik Jenis Pekerjaan Responden

\begin{tabular}{clcc}
\hline No. & Jenis Pekerjaan & Jumlah & Persentase (\%) \\
\hline 1. & Pelajar/Mahasiswa & 8 & 16,3 \\
\hline 2. & Pegawai Swasta & 10 & 20,4 \\
\hline 3. & PNS/TNI/POLRI & 3 & 6,1 \\
\hline 4. & Wiraswasta/Usahawan & 6 & 12,2 \\
\hline $\mathbf{5 .}$ & Ibu rumah tangga & 18 & 36,7 \\
\hline $\mathbf{6 .}$ & Petani & 4 & 8,2 \\
\hline Total & & 49 & 100 \\
\hline
\end{tabular}

Sumber : Data Primer, 2018

Berdasarkan tabel 4 diatas diketahui bahwa dari 49 responden yang sering melakukan pemeriksaan rutin ke laboratorium rumah sakit muhammadiyah ahmad dahlan kota kediri adalah Ibu rumah tangga (IRT) yaitu sebanyak 18 responden $(36,7 \%)$. 
Petro Dwi Siswanto, Oktovina Rizky Indrasari, Elok Retno anggraini / Jurnal Analis Kesehatan Klinikal Sains 7 (2) (2019)

e. Karakteristik jumlah kunjungan responden yang melakukan pemeriksaan ke laboratorium rumah sakit muhammadiyah ahmad dahlan kota kediri

Tabel 5. Karakteristik jumlah kunjungan responden

\begin{tabular}{rccc}
\hline No. & Jenis Kunjungan & Jumlah & Persentase (\%) \\
\hline $\mathbf{1 .}$ & Pertama Kali & 13 & 26.5 \\
\hline $\mathbf{2 .}$ & Kedua Kali & 17 & 34.7 \\
\hline $\mathbf{3 .}$ & Lebih dari 2x & 12 & 24.5 \\
\hline 4. & Kunjungan Rutin & 7 & 14.3 \\
\hline Total & & 49 & 100 \\
\hline
\end{tabular}

Sumber : dara primer 2018

Berdasarkan tabel 5 diatas diketahui bahwa dari 49 responden yang melakukan kunjungan ke Laboratorium Rumah Sakit Muhammadiyah Ahmad Dahlan Kota Kediri yaitu sebagian besar responden melakukan kunjungan sebanyak dua laki $(34,7 \%)$ dan sebagian kecil responden yang melakukan kunjungan rutin $(14,3 \%)$.

Kualitas Pelayanan Di Laboratorium Rumah Sakit Muhammadiyah Ahmad Dahlan Kota Kediri.

Tabel 6. Kualitas Pelayanan

\begin{tabular}{cccc}
\hline No. & Kategori & Frekuensi & Persentase (\%) \\
\hline $\mathbf{1 .}$ & Baik & 45 & 91,8 \\
\hline $\mathbf{2 .}$ & Tidak Baik & 4 & 8,2 \\
\hline
\end{tabular}

Sumber : Data Primer, 2018

Berdasarkan tabel 6. diatas menjelaskan bahwa responden yang menyatakan kualitas pelayanan baik adalah sebanyak 45 responden $(91,8 \%)$.

f. Loyalitas Pelanggan Laboratorium Di Laboratorium Rumah sakit Muhammadiyah Kota Kediri.

Tabel 7. Loyalitas Pelanggan

\begin{tabular}{cccc}
\hline No. & Kategori & Frekuensi & Persentase (\%) \\
\hline 1. & Ya & 44 & 89,8 \\
\hline 2. & Tidak & 5 & 10,2
\end{tabular}

Sumber : Data Primer, 2018 
Petro Dwi Siswanto, Oktovina Rizky Indrasari, Elok Retno anggraini / Jurnal Analis Kesehatan Klinikal Sains 7 (2) (2019)

Berdasarkan tabel 7 diatas menjelaskan bahwa responden yang menyatakan Loyalitas tehadap Laboratorium Rumah Sakit Muhammadiyah Ahmad Dahlan Kota Kediri sebanyak 44 responden $(89,8 \%)$. Hal ini menunjukkan bahwa responden di Laboratorium Rumah Sakit Muhammadiyah Ahmad Dahlan Kota Kediri memiliki pelanggan yang loyal.

g. Analisis Kualitas Pelayanan Laboratorium Dengan Loyalitas Pelanggan Laboratorium Di Rumah Sakit Muhammadiyah Ahmad Dahlan Kota Kediri.

Tabel 8. Analisa Kualitas Pelayanan Laboratorium Dengan Loyalitas Pelanggan Laboratorium Di Rumah Sakit Muhammadiyah Ahmad Dahlan Kota Kediri.

\begin{tabular}{|c|c|c|c|c|c|c|}
\hline \multirow[t]{3}{*}{ No. } & \multirow{3}{*}{$\begin{array}{l}\text { Kualitas } \\
\text { Pelayanan }\end{array}$} & \multicolumn{4}{|c|}{ Loyalitas Pelanggan } & \multirow[t]{3}{*}{ Jumlah } \\
\hline & & \multirow{2}{*}{$\begin{array}{l}\text { Ya } \\
\text { Jumlah }\end{array}$} & \multicolumn{3}{|c|}{ Tidak } & \\
\hline & & & $\%$ & Jumlah & $\%$ & \\
\hline 1. & Baik & 42 & 93,3 & 3 & 6,7 & 45 \\
\hline 2. & Tidak Baik & 2 & 50,0 & 2 & 50,0 & 4 \\
\hline
\end{tabular}

$$
\alpha: 0,05
$$

Sig :0,047

\footnotetext{
Sumber : Data Primer

Dari tabel 8 menunjukan bahwa responden yang bersifat loyalitas dan serta menyatakan kualitas pelayanan baik sebanyak 42 responden (93,3\%). Pada uji statistik menggunakan uji chi square di dapatkan nilai sig $=0,047<\alpha=0,05$ yang artinya adanya hubunga antara kualitas pelayanan dengan loyalitas pelanggan Laboratorium di Rumah Sakit Muhammadiyah Ahmad Dahlan Kota Kediri.
}

\section{PEMBAHASAN}

Penelitian ini mengenai hubungan kualitas pelayanan laboratorium dengan loyalitas pelanggan laboratorium di Rumah Sakit muhammadiyah ahmad dahlan kota Kediri. Kualitas pelayanan dapat dilihat dari 5 dimensi yaitu dari dimensi bukti fisik, keandalan, ketanggapan, jaminan, dan empati. dari dimensi bukti fisik menunjukan bahwa laboratorium memperhatikan sarana dan prasarana yang menunjang kualitas pelayanan tersebut. Seperti fasilitas ruang tunggu yang memadai dan selalu terjaga kebersihan, serta penampilan petugas laboratorium yang selalu berpenampilan rapi. Dimensi keandalan menunjukkan bahwa petugas memberikan pelayanan yang cepat dan tepat waktu, artinya petugas memberikan kejelasan akan lamanya waktu tunggu pemeriksaan kepada pelanggan. Hal tersebut sudah sesuai dengan apa yang telah dilakukan oleh petugas laboratorium Rumah Sakit Muhammadiyah Ahmad Dahlan Kota Kediri. Dimensi 
ketanggapan dapat dilihat bahwa petugas mampu menyelesaikan keluhan-keluhan pelanggan dan juga petugas sangat cepat dalam melakukan tindakkan terhadap pelanggan, sehingga pelanggan tidak lama dalam menunggu. Dimensi jaminan dapat dilihat bahwa petugas selalu sopan dalam betutur kata maupun dalam penampilan sehingga membuat pelangan merasa nyaman. Dilihat pula dari dimensi empati dapat dilihat bahwa petugas selalu menanyakan kondisi pelanggan, bersikap ramah dan sopan dalam melayani pelanggan. Hal tersebut sudah sesuai dengan hasil penelitian yang dilakukan oleh peneliti dengan hasil 91,8 \% pelanggan yang menilai bahwa kualitas pelayanan sudah sangat baik.

Loyalitas pelanggan laboratorium dapat di lihat dari kunjungan ulang, pelayanan laboratorium, dan penolakan berpindah tempat pemeriksaan lain. Kunjungan ulang dapat di lihat dari banyak pelanggan yang sering melakukan chek-up rutin di laboratorium tersebut. Dari pelayanan laboratorium banyak pelanggan yang menjadikan Laboratorium Rumah Sakit Ahmad Dahlan Kota Kediri adalah pilihan utama dalam melakukan pemeriksaan Laboratorium, hal itu dikarenakan pelayanan yang diberikan sudah sangat baik sehingga membuat pelanggan nyaman pada saat melakukan pemerikssaan di laboratorium rumah sakit muhammadiyah ahmad dahlan kota Kediri. Pada penolakan berpindah tempat pemeriksaan banyak pelanggan yang lebih memilih untuk tetap melakukan pemeriksaan di laboratorium rumah sakit ahmad dahlan kota Kediri dikarenakan Pelanggan sudah nyaman dengan pelayanan serta keramahan yang di berikan oleh petugas Laboratorium Rumah Sakit tersebut, sehingga mereka tidak ada niatan untuk berganti tempat pemeriksan Laboratorium. Hal tersebut sudah sesuai dengan hasil penelitian yang dilakukan oleh peneliti dengan hasil sebanyak 89,8\% pelanggan sangat loyal terhadap laboratorium Rumah Sakit Muhammadiyah Ahmad Dahlan Kota Kediri.

Berdasarkan hasil penelitian tentang loyalitas pelanggan Laboratorium Di Rumah Sakit Muhamadiyah Ahmad Dahlan Kota Kediri adalah responden sangat loyalitas terhadap Rumah Sakit Muhamadiyah Ahmad Dahlan Kota Kediri, dapat dilihat dari pernyataan responden yang menyatakan loyalitas sebesar 93,3\%. Hasil penelitian dapat menunjukkan bahwa pelanggan merasa puas setelah membeli/menggunakan produk jasa di Laboratorium Rumah Sakit Muhammadiyah Ahmad Dahlan Kota Kediri. Hal ini sejalan dengan teori yang di kemukakan oleh Bustami bahwa kenyamanan dapat juga mempengaruhi kepuasan pelanggan yang menjadi tolak ukur kualitas pelayanan (Bustami, 2011)

Hal ini menunjukkan bahwa pelayanan yang diberikan mampu memenuhi harapan dari pelanggan. Hasil penelitian ini sesuai dengan penjelasan dalam landasan teori menurut Muninjaya (2015) jasa pelayanan kesehatan akan dirasakan berkualitas oleh para pelanggannya jika hal-hal yang disampaikan kepada para penggunanya melebihi harapan, maka Laboratorium Rumah Sakit Muhammadiyah Ahmad Dahlan Kota Kediri harus mampu mempertahankan dan 
meningkatkan kualitas pelayanan dengan cara selalu merancang kualitas jasa dengan baik dan mengendalikan keunggulannya untuk dapat memenuhi harapan para pengguna jasa kesehatan.

Pada pengujian hipotesis dengan uji chi-square didapatkan nilai sig $=0,047$ (dengan derajat kemaknaan $<0,05)$, sehingga sig $=0,047<0,05$, dan $r=0,365$ yang artinya terdapat hubungan antara kualitas pelayanan laboratorium dengan loyalitas pelangan laboratorium dengan arah korelasi positif dan menunjukkan dengan demikian H0 ditolak dan H1 diterima. Penelitian ini sesuai dengan yang dilakukan oleh beberapa peneliti yakni pada Santoso (2013) yaitu adanya pengaruh kualitas pelayanan terhadap loyalitas pelanggan laboratorium klinik populer Surabaya, penelitian yang dilakukan Hamidiyah (2013) dengan hasil bahwa adanya hubungan antara kualitas pelayanan dengan minat kunjungan ulang di Klinik Umum RS Bhineka Bhakti Husada Kota Tangerang Selatan. Penelitian yang dilakukan oleh Aryani (2010) dengan hasil adanya Pengaruh Kualitas Layanan terhadap Kepuasan Pelanggan dalam Membentuk Loyalitas Pelanggan.

Hasil penelitian mereka menunjukan bahwa kualitas pelayanan memiliki hubungan yang kuat dengan loyalitas pelanggan pada saat mendapatkan pelayanan. Hal ini sejalan dengan teori yang di kemukakan oleh Oswald S.L et all, 1998 dalam (Hamidiyah, 2013) Pengalaman pelanggan terhadap kualitas pelayanan kesehatan pertama yang dirasakan akan berpengaruh terhadap minat kunjungan ulang.

\section{SIMPULAN}

Berdasarkan hasil peneliian yang diperoleh maka dapat disimpulkan sebagai berikut.

1. Kualitas pelayanan berdasarkan daya tanggap dari petugas di Laboratorium Rumah Sakit Muhammadiyah Ahmad Dahlan Kota Kediri adalah memuaskan.

2. Kualitas pelayanan berdasarkan kehandalan dari petugas di Laboratorium Rumah Sakit Muhammadiyah Ahmad Dahlan Kota Kediri adalah memuaskan.

3. Kualitas pelayanan berdasarkan jaminan dari petugas di Laboratorium Rumah Sakit Muhammadiyah Ahmad Dahlan Kota Kediri adalah memuaskan.

4. Kualitas pelayanan berdasarkan empati dari petugas di Laboratorium Rumah Sakit Muhammadiyah Ahmad Dahlan Kota Kediri adalah memuaskan.

5. Kualitas pelayanan berdasarkan bukti fisik dari petugas di Laboratorium Rumah Sakit Muhammadiyah Ahmad Dahlan Kota Kediri adalah memuaskan.

6. Terdapat hubungan antara kualitas pelayanan Laboratorium dengan loyalitas pelanggan Laboratorium Di Rumah Sakit Muhammadiyah Ahmad Dahlan Kota Kediri.

\section{UCAPAN TERIMA KASIH}


Petro Dwi Siswanto, Oktovina Rizky Indrasari, Elok Retno anggraini / Jurnal Analis Kesehatan Klinikal Sains 7 (2) (2019)

Ucapan terima kasih kepada pihak Laboratorium Rumah Sakit Muhammadiyah Ahmad Dahlan Kota Kediri yang telah membantu dan bekerjasama demi kelancaran penelitian ini.

\section{DAFTAR PUSTAKA}

Afif Ghaffar Ramadhan. 2017. Analisis Pengaruh Kualitas Produk, Kualitas Pelayanan, dan Citra Merek terhadap Minat Beli Ulang pada Sepatu Nike Running di Semarang melalui Kepuasan Pelanggan sebagai Variabel Intervening. Diponegoro Journal of Management, Volume 6, Nomor 1,

Anggraini. Merry, T. dan Rohmani, A. 2012. Hubungan Kepuasan Pasien dengan Minat Pasien dalam Pemanfaatan Ulang Pelayanan Kesehatan pada Praktek Dokter Keluarga, Jurnal Unimus. Semarang : Fakultas Kedokteran Universitas Muhammadiyah Semarang.

Aryani.2010. judul jurnal. Pengaruh Kualitas Layanan terhadap Kepuasan Pelanggan dalam Membentuk Loyalitas Pelanggan, Jurnal Ilmu Administrasi dan Organisasi Vol 17, No 2

Aulia Nur Hidayati. 2014. Analisis Hubungan Karakteristik Pasien Dengan Kepuasan Pelayanan Rawat Jalan Semarang Eye Center (SEC) Rumah Sakit Islam Sultan Agung Semarang

Bustami. 2011. Penjaminan Mutu Pelayanan Kesehatan \& Akseptabilitasnya. Jakarta: Erlangga. Farich, A. 2012. Managemen Pelayan Kesehatan Masyarakat. Yogyakarta:Gosyen Publishing. Hamidayah, Azizatul. 2013. Hubungan Persepsi Pasien Tentang Kualitas Pelayanan dengan Minat Kunjungan Ulang di Klinik Umum RS Bhineka Bakti Husada Kota Tangerang Selatan Tahun 2013. Skripsi.

Jatmiko dwi. 2012., Kualitas Pelayanan Dan Kepuasan Pelanggan Sebagai Anteseden Loyalitas Pelanggan, Jurnal Manajemen Bisnis Vol.2 No.01

Khairunnisa. 2014. Pengaruh Switching Barrier Terhadap Loyalitas Nasabah Asuransi Pendidikan AJB Bumiputra.

Muninjaya. 2015. Manajemen Mutu Pelayanan Kesehatan. Jakarta : EGC.

Notoatmodjo,Soekidjo. 2010. Metodoogi Penelitian Keehatan. Jakarta : Renika Cipta 